\title{
Method to Estimate the Population Density of the Snow Crab Chionoecetes opilio Using a Deep-Sea Video Monitoring System on a Towed Sledge
}

\author{
Toshihiro WATANABE* \\ Fishing Technology Division, National Research Institute of Fisheries Engineering, \\ Fisheries Research Agency (Ebidai, Hasaki, Kashima, Ibaraki 314-0421, Japan)
}

\begin{abstract}
A deep-sea video monitoring system on a towed sledge (DVMSTS) was developed to estimate the population density of the snow crab Chionoecetes opilio. Population density of the snow crab was investigated using the DVMSTS in a practical survey. The observations were carried out at 7 survey sites ranging from 200 to $340 \mathrm{~m}$ in depth on August 20-29, in 1998. These sites were located off both northern and western Oki Islands in the Sea of Japan. The observations were repeated 8 times and video tapes were recorded for $375 \mathrm{~min}$ in total. The observed distances were $15,600 \mathrm{~m}$ in total, and the towed DVMSTS was able to sweep the sea bottom over an area of $25,900 \mathrm{~m}^{2}$. Sweeping area was obtained by multiplying the observed distance by the width of the DVMSTS (1.66 m). A count of 104 crabs was recorded. Crab densities per $1,000 \mathrm{~m}^{2}$ for each observation were estimated to be $1,3,3,3.1$, 4.0, 5.6, 6.4 and 10 individuals, respectively. Sex of small crabs less than about $9 \mathrm{~cm}$ in carapace width could not be defined from the recorded video images. Because the majority of the crabs did not respond to the light, it was assumed that underwater light hardly affected the crab behavior. The method to estimate the population density of the snow crab using the DVMSTS can be effective, especially for a quantitative survey of the stock abundance of the snow crab.
\end{abstract}

Discipline: Fisheries

Additional key words: stock abundance, Sea of Japan, megalobenthos

\section{Introduction}

The snow crab Chionoecetes opilio is widely distributed along the Alaska coast and Greenland west coast in the Arctic Ocean, North America coast in the Atlantic Ocean and Pacific Ocean, in the Bering Sea, in the Sea of Okhotsk, in the Sea of Japan and along the Japanese coast in the northern Pacific Ocean from Chiba prefecture ${ }^{12)}$. Especially in Japan, this crab has been mainly caught by trawl in the Sea of Japan. The crab habitat is located at a depth between 200 and $450 \mathrm{~m}$, at the margin of the continental shelf in the Sea of Japan and Yamatotai (bank) in the center of the Sea of Japan, where the water temperature is less than $5^{\circ} \mathrm{C}^{12)}$. The crab is a very important resource for the fisheries industry. A peak landing of about $15,100 \mathrm{t}$ of the snow crab occurred in 1964. However, the landings have decreased since 1964, for example, to $9,900 \mathrm{t}$ in 1967 , and to 5,000 $\mathrm{t}$ in 1976. In recent years, landings have ranged between 1,900 and 3,700 t.
To ensure long-term sustainable use of this resource, it is necessary to promote a better management of the crab population under the TAC (Total Allowable Catch) control system based on the accurate estimation of the stock abundance. The stock abundance of the snow crab has been estimated based on trawl and pot surveys.

However, there have been some problems in terms of quantitative sampling because the sampling efficiency of such fishing gear has not been sufficiently quantified ${ }^{6,16)}$. To complement the quantitative reliability of sampling of the survey fishing gear, the use of manned deep submersible and towing deep sea TV system (with an umbilical cable) has been an effective method to estimate the distribution density of the megalobenthos ${ }^{6,19)}$. The Deep-Sea Video Monitoring System on a Towed Sledge (DVMSTS) was developed to estimate the density of the red queen crab Chionoecetes japonicus and its effectiveness was demonstrated in field observations ${ }^{20)}$. Fujikura et al. ${ }^{3)}$ also revealed that the population density of the red queen crab could be accurately estimated with-

*Corresponding author: fax +81-479-44-1875; e-mail tosihiro@affrc.go.jp

Received 10 May 2001; accepted 2 July 2001. 
out biases by an in situ observation method. However, since the mounting position of the underwater video camera of the DVMSTS for the red queen crab was low, the photographic range was narrow and the practicability was low. To enhance the practicability as a method of estimating the snow crab population density, the DVMSTS was improved to extend the photographic range. In this study, we investigated the population density of the snow crab by using the DVMSTS and evaluated its effectiveness and practicability as an estimation method.

\section{Experimental method}

The survey for estimating the density of the snow crab using DVMSTS (Fig. 1) was carried out on the research vessel Mizuho-maru (belonging to Japan Sea National Fisheries Research Institute, 156 GT) from August 20 to 29 in 1998. Sea bottom observation was performed 8 times in total at 7 locations (M1-M7, Fig. 2) off both northern and western Oki Islands in the Sea of Japan (Table 1).

The DVMSTS made of stainless steel $(151 \mathrm{~cm}$ in height, $166 \mathrm{~cm}$ in width and $252 \mathrm{~cm}$ in length) is equipped with an underwater video camera and underwater light source, with an air weight of about $270 \mathrm{~kg}$ (Fig. 3). The video camera (Sony model Handycam CCDTR3300), with a wide conversion lens (Sony VCL-0552) is stored in a watertight casing attached at the center of

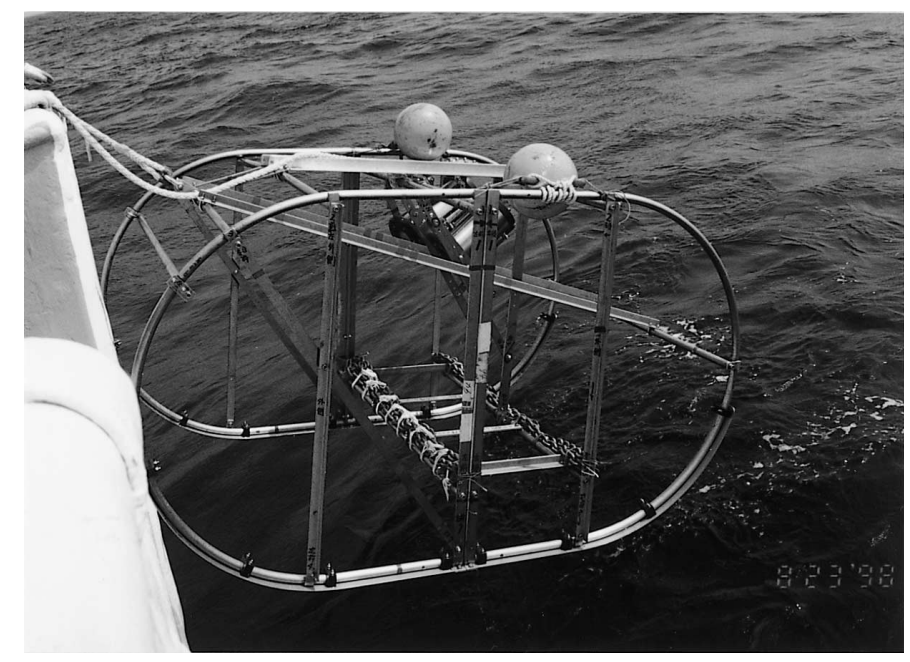

Fig. 1. Photograph of the deep-sea video monitoring system on a towed sledge on the R/V Mizuho-maru

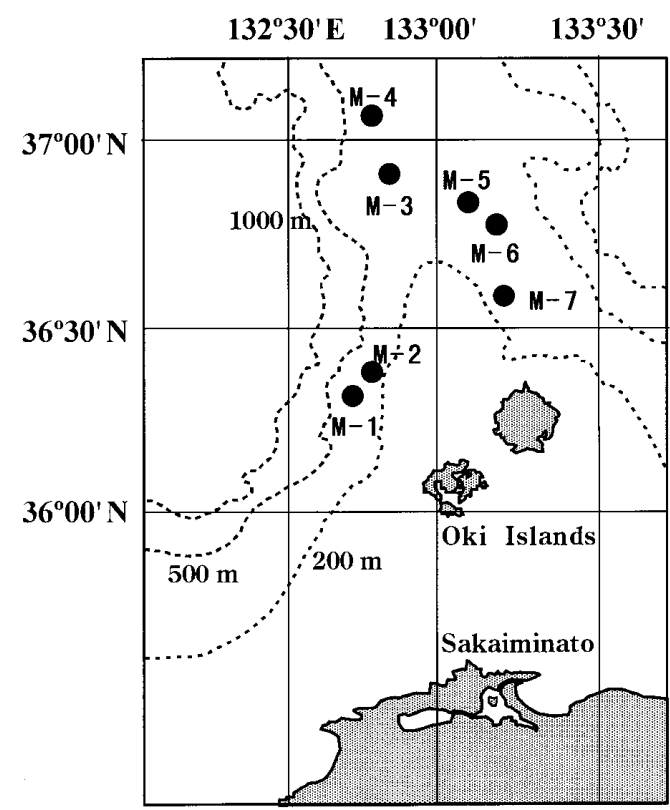

Fig. 2. Map showing the survey sites off northern and western Oki islands

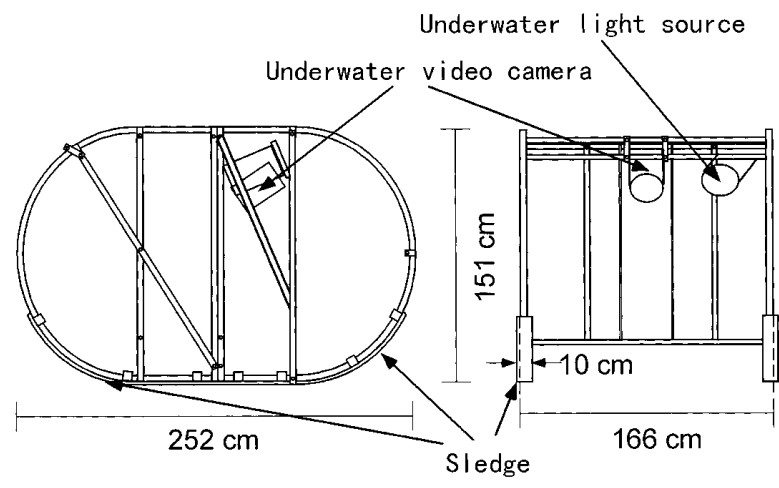

Fig. 3. Schematic drawing of the deep-sea video monitoring system on a towed sledge 
Table 1. Number of snow crabs observed and towing characteristics of the deep-sea video monitoring system on a towed sledge

\begin{tabular}{|c|c|c|c|c|c|c|c|c|}
\hline Station number & M-1 & M-1 & M-2 & M-3 & M-4 & M-5 & M-6 & M-7 \\
\hline Date of observation ( in 1998 ) & August 29 & August 29 & August 28 & August 21 & August 20 & August 26 & August 25 & August 23 \\
\hline Survey site $^{\text {a) }}$ N.L. ${ }^{\text {b) }}$ & $36^{\circ} 18.3^{\prime}$ & $36^{\circ} 18.0^{\prime}$ & $36^{\circ} 22.5^{\prime}$ & $36^{\circ} 53.6^{\prime}$ & $37^{\circ} 03.4^{\prime}$ & $36^{\circ} 50.3^{\prime}$ & $36^{\circ} 46.1^{\prime}$ & $36^{\circ} 35.0^{\prime}$ \\
\hline E.L. ${ }^{c)}$ & $132^{\circ} 42.9^{\prime}$ & $132^{\circ} 43.3^{\prime}$ & $132^{\circ} 46.6^{\prime}$ & $132^{\circ} 49.4^{\prime}$ & $132^{\circ} 46.5^{\prime}$ & $133^{\circ} 04.8^{\prime}$ & $133^{\circ} 10.8^{\prime}$ & $133^{\circ} 12.4^{\prime}$ \\
\hline Bottom depth (m) & $295-335$ & $285-287$ & $250-255$ & $274-279$ & $308-314$ & $257-260$ & $245-267$ & $207-208$ \\
\hline Observation time :start & $10: 57$ & $12: 48$ & $11: 38$ & $12: 53$ & $11: 30$ & 13:06 & $11: 00$ & $14: 35$ \\
\hline :end & $11: 57$ & $13: 48$ & $12: 38$ & $13: 53$ & $12: 20$ & $13: 11$ & $12: 00$ & $14: 55$ \\
\hline Duration (min) & 60 & 60 & 60 & 60 & 50 & $5^{\text {d) }}$ & 60 & $20^{\mathrm{e})}$ \\
\hline Speed (knot) & 1.2 & 1.4 & 1.3 & 0.8 & 1.1 & 1.7 & 2.0 & 1.7 \\
\hline Observed distance $(\mathrm{m})$ & 2,300 & 2,600 & 2,500 & 1,500 & 1,700 & 300 & 3,700 & 1,000 \\
\hline Observed area $\left(\mathrm{m}^{2}\right)$ & 3,800 & 4,300 & 4,200 & 2,500 & 2,800 & 500 & 6,100 & 1,700 \\
\hline Number of crabs & 4 & 17 & 13 & 7 & 18 & 6 & 34 & 5 \\
\hline Density of crabs (No./1,000 $\mathrm{m}^{2}$ ) & 1 & 4.0 & 3.1 & 3 & 6.4 & 10 & 5.6 & 3 \\
\hline
\end{tabular}

a): Locations were determined with GPS (Global Positioning System).

b): North latitude.

c): East longitude.

d): Since the trawl warp was paid out over a long distance, the trawl warp came into contact with the sea bed. The observation lasted from the start of photography to the time when the trace generated by the trawl warp on the sea bed was observed on the video image.

e): Since the trawl warp was paid out over a short distance, the trawl warp was paid out again during the observation. The observation lasted from the time when the trawl warp was paid out again to the time when photography ended.

the DVMSTS. The power source of the video camera is supplied by battery packs (Sony Ltd. NP-710), and the video camera is switched on and off with a timer (Goto Aquatics Co., Ltd. GTO-CTW 1) ${ }^{7,8)}$. The light source (a halogen lamp, DC 24 voltage, 150 wattage) and 2 battery packs (Paco Electronics Ltd. DP-55 12 V 5.5 Ah) as power sources are stored in another watertight casing. The on/off switch of the light is also operated with a timer (Goto Aquatics Co., Ltd. GTO-LTW 1) ${ }^{7,8)}$. These watertight casings can be used for depths up to $1,100 \mathrm{~m}$. The DVMSTS is basically the same system as that used for observing the red queen crab distribution ${ }^{20)}$. In the present study, however, the DVMSTS was improved to extend the photographic range and focus easily on the observation zone. The underwater video camera was set so that both sledges of the DVMSTS could come into the field of view of the underwater video camera (Fig. 4).

The DVMSTS was towed with the trawl warp (14 $\mathrm{mm}$ in diameter). When the trawl warp came into contact with the sea bed, the trawl warp threatened crabs and they ran away from the observation zone. A nylon cross rope (60 $\mathrm{m}$ in length, $26 \mathrm{~mm}$ in diameter) was inserted between the trawl warp and the DVMSTS to prevent the trawl warp from coming into contact with the sea bed. Towing speed ranged between 1 and 2 knots. The ratio of the length of the trawl warp with the inserted nylon rope to the water depth was about 1.5 . Recording time of one observation varied from 40 to $60 \mathrm{~min}$ depending on the capacity of the batteries. The depth of the water surveyed was measured with a fish finder (Furuno Co., Ltd. FE$822 \mathrm{CT}$ ). The position of the research vessel was determined with the GPS (Global Positioning System Furuno Co., Ltd GP-80). The timers of the underwater video camera and of the underwater light were started on simultaneously immediately before the DVMSTS was put into the sea. Photography was started after 20 or $30 \mathrm{~min}$, because the research vessel required such a time interval to reach a steady course and constant speed. The position

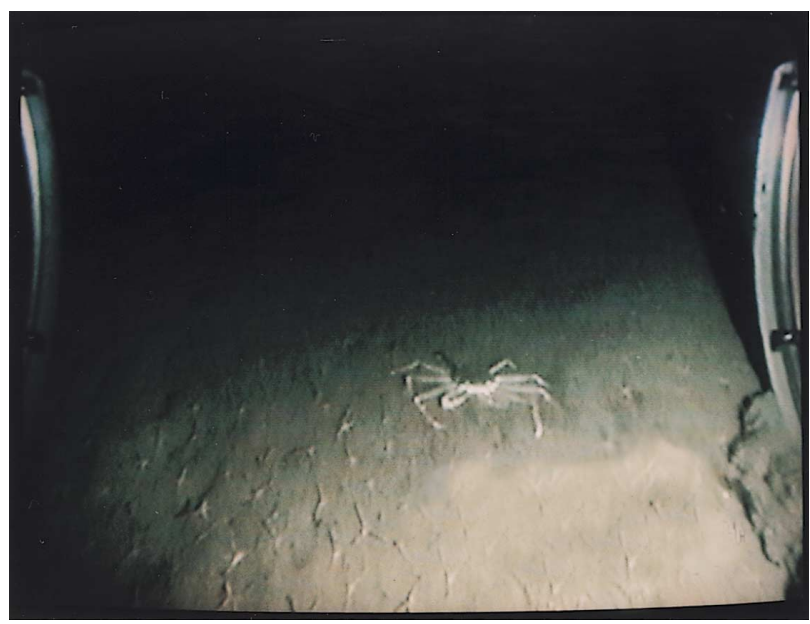

Fig. 4. Example of the video image recorded with the deepsea video monitoring system on a towed sledge 


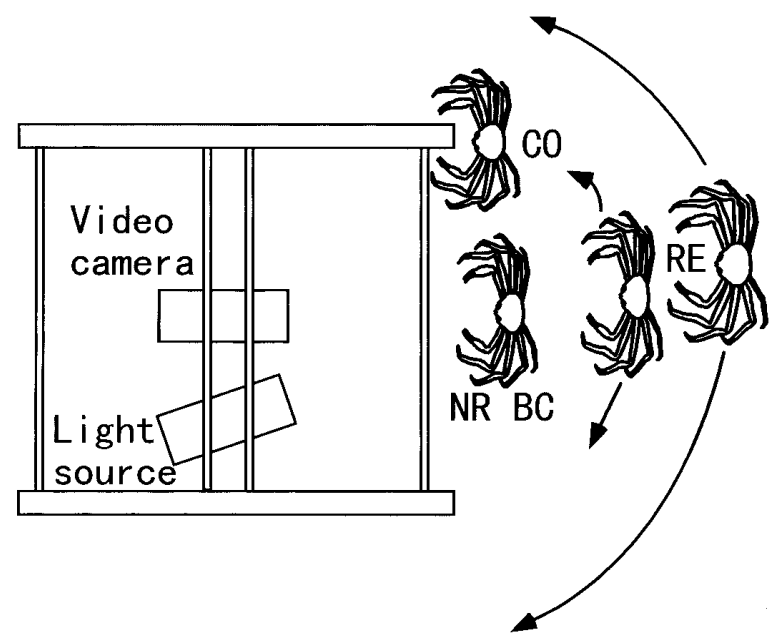

Fig. 5. Schematic illustration of behavioral response of the snow crab to the deep-sea video monitoring system on a towed sledge

NR: No response (no movement),

RE: Response (movement),

$\mathrm{CO}$ : Contact with the sledge without response,

BC: Partially buried crab (when the crab was partly buried, both parts of the carapace and parts of the legs were exposed or only the carapace was exposed).

of the research vessel and the depth were recorded every $5 \mathrm{~min}$. This position was recorded in relation to the position of the DVMSTS. The towing distance was calculated based on the position where photography started and ended. In this study, only the crabs that were observed within the observation zone $(1.66 \mathrm{~m}$, observation width, Fig. 3) between the towed sledges were counted. Sweeping area was obtained by multiplying the observed distance (towing distance) by the width of the DVMSTS $(1.66 \mathrm{~m})$. Since the estimation accuracy of the position measured with the GPS was within $100 \mathrm{~m}^{14)}$, the towing distance (round off less than $100 \mathrm{~m}$ ) and the sweeping area (round off less than $100 \mathrm{~m}^{2}$ ) were obtained. The water temperature near the sea bed of the surveyed area was measured with a CDT (Nell Brown Co., Ltd. MarkIII). The number of crabs was counted based on the video images on the recording tape and the number of individuals per $1,000 \mathrm{~m}^{2}$ was calculated from the sweeping area.

The estimation accuracy of the population density appeared to be affected by the crab response to the light and the approach of the sledges because the field of view of the underwater video camera was limited. To examine the effect of the underwater light and the approach of sledges on the crab behavior, the crab behavior was categorized into 4 groups as follows (Fig. 5): 1) No response (no movement); 2) Contact with the sledge without response; 3) Partially buried crab, when the crab was partly buried, both parts of the carapace and parts of the legs were exposed or only the carapace was exposed; 4) Response (movement).

\section{Results}

The observations were repeated 8 times and the video images were recorded for $375 \mathrm{~min}$ in total. An example of the video image recorded with the DVMSTS is shown in Fig. 4. The observed distances were 15,600 $\mathrm{m}$ in total, and the towed DVMSTS was able to sweep the sea bottom over a total area of $25,900 \mathrm{~m}^{2}$. A count of 104 crabs was recorded. Sex of small crabs less than about 9 $\mathrm{cm}$ in carapace width could not be estimated from the recorded video images. The water temperature near the sea bottom of the water surveyed ranged from 0.7 to 2.2 ${ }^{\circ} \mathrm{C}$. Based on the recorded video images, the towed sledge was stabilized and towed along a nearly straight line. The bottom of the sea area surveyed was almost flat and consisted of soft mud. Numerous traces were observed as various organisms moved on the sea bed and also numerous small burrows of the organisms were observed. Components of the megalo-epibenthos which were frequently observed except for the snow crabs included Zoarcidae, Asteroidea, Ophiuroidea, Antedonidae, Paguridea, Macrura, Buccinidae, Pennatulacea, Actiniaria. In particular, Liponema multicornis was frequently observed.

\section{1) Density of snow crabs}

Table 1 shows the towing characteristics such as the position of the surveyed sea area, towing speed, towing distance, sweeping area, number of snow crabs and number of individuals per $1,000 \mathrm{~m}^{2}$, etc. Since a significant figure corresponded to one digit in the surveyed sea area where the number of observed crabs was less than 10 individuals, similarly, the number of individuals per $1,000 \mathrm{~m}^{2}$ was indicated by one digit. Sweeping area in the surveys ranged from 500 to $6,100 \mathrm{~m}^{2}$. The number of individuals observed in each area ranged from 4 to 34 individuals. The density of the snow crabs ranged from 1 individual $/ 1,000 \mathrm{~m}^{2}$ at $\mathrm{M}-1$ to 10 individuals $/ 1,000 \mathrm{~m}^{2}$ at M-5.

\section{2) Crab behavior}

Crab behavior is presented in Table 2. Out of a total of 104 individuals, 88 individuals ( $85 \%$ ) did not respond to the towed sledge when it came close to the crabs. On the other hand, 16 individuals moved to avoid the towed sledge that was close to the crabs. Out of these 16 individuals, 15 individuals began to move after crabs had 
Table 2. Behavioral response of the snow crabs to the deep-sea video monitoring system on a towed sledge

\begin{tabular}{lccccccccc}
\hline \hline Station number & M-1 & M-1 & M-2 & M-3 & M-4 & M-5 & M-6 & M-7 & Total \\
\hline No response ( no movement ) & 1 & 7 & 6 & 2 & 10 & 3 & 28 & 1 & 58 \\
Contact with the sledge without response & 2 & 1 & 3 & 2 & 0 & 0 & 0 & 0 & 8 \\
Partially buried crab* & 0 & 7 & 0 & 1 & 3 & 2 & 6 & 3 & 22 \\
Response ( movement ) & 1 & 2 & 4 & 2 & 5 & 1 & 0 & 1 & 16 \\
Total & 4 & 17 & 13 & 7 & 18 & 6 & 34 & 5 & 104 \\
\hline
\end{tabular}

*When the crab was partly buried, both parts of the carapace and parts of the legs were exposed or only the carapace was exposed.

been within the field of view of the underwater video camera. One individual among the remainder had already moved by the time it came into the field of view of the underwater camera. It was possible to determine whether such a crab had been in the observation zone based on the dust generated by the crab movement.

\section{Discussion}

Population density of the snow crab in the Sea of Japan has been estimated from observations using the deepsea research submersible "SHINKAI 2000"6,9,10,15,17,18). The results are summarized in Table $3^{6,9,10,15,17,18)}$. The population density per $1,000 \mathrm{~m}^{2}$ was estimated to be about 5 individuals. However, the estimation range markedly fluctuated from 0.3 to 34.8 individuals depending on the area surveyed. Similarly, the number of observed individuals per $1,000 \mathrm{~m}^{2}$ estimated in this study ranged between 1 and 10 individuals depending on the area. These estimation values were also within the range of those recorded using "SHINKAI 2000". Therefore, the results obtained with the DVMSTS appeared to be consistent with the values estimated in these studies.

Subsequently, we determined whether the light and the approach of the towed sledges affected the snow crab behavior. Many crabs did not respond to the towed sledges that were coming close to them in this study. On the other hand, crabs that had moved to avoid the towed sledge began to move after coming into the field of view of the underwater video camera. There was only one crab that had already moved when it came into the field of view of the underwater video camera. Although deepsea organisms had been observed with "SHINKAI 2000" and ROVs (remotely operated vehicles) using a light, the light may have hardly affected the behavior of the organisms ${ }^{2,6,11)}$. Most of the red queen crabs also did not respond to the light of the DVMSTS ${ }^{20)}$. Miller suggested that the flash did not induce the crabs to move away, in his report on the density of the snow crab population estimated using the underwater camera with a $100 \mathrm{~W}$-second strobe light ${ }^{13)}$. Therefore, it is suggested that the light hardly affected the crab behavior. Based on the above results, it appears that 16 individuals which moved, actually reacted to the approach of the towed sledge. Since the field of view of the underwater video camera of the DVMSTS was in front of the sledge, it was possible to determine whether the crabs had been in the observation zone before the towed sledge reached the crabs. Most of the crabs that had moved to avoid the towed sledge began to move after they came into the field of view of the underwater video camera. Hence, it is considered that the underwater video camera enabled to take video images of almost all the crabs in the observation zone before the crab behavior was affected by the approach of the towed

Table 3. Population density of the snow crabs at different locations of the Sea of Japan observed with SHINKAI 2000

\begin{tabular}{|c|c|c|c|c|c|}
\hline \multirow[t]{2}{*}{ Survey area } & \multicolumn{2}{|c|}{ Locations } & \multirow{2}{*}{$\begin{array}{l}\text { Bottom depth } \\
\text { (m) }\end{array}$} & \multirow{2}{*}{$\begin{array}{c}\text { Density of crabs } \\
(\text { Number/1,000 m²) }\end{array}$} & \multirow[t]{2}{*}{ References } \\
\hline & North latitude & East longitude & & & \\
\hline Toyama Bay & $37^{\circ} 20^{\prime}$ & $137^{\circ} 32^{\prime}$ & $266-290$ & 5.1 & Hashimoto \& Hotta $^{6}$ \\
\hline Toyama Bay & $36^{\circ} 50^{\prime}$ & $137^{\circ} 15^{\prime}$ & $357-420$ & 34.8 & Hashimoto \& Hotta ${ }^{6}$ \\
\hline Toyama Bay & $37^{\circ} 13^{\prime}$ & $137^{\circ} 16^{\prime}$ & $458-585$ & 1.9 & Hashimoto \& Hotta ${ }^{6}$ \\
\hline Wakasa bay & $35^{\circ} 52^{\prime}$ & $135^{\circ} 43^{\prime}$ & $232-237$ & 5.2 & Ryoke $^{7)}$ \\
\hline Off Hinomisaki & $35^{\circ} 48^{\prime}$ & $132^{\circ} 23^{\prime}$ & $254-259$ & 5.6 & Kanamaru and Adachi ${ }^{9)}$ \\
\hline Off Kaga & $36^{\circ} 42^{\prime}$ & $136^{\circ} 43^{\prime}$ & $228-242$ & 0.3 & Ohashi $^{15)}$ \\
\hline Off Wakasa Bay & $36^{\circ} 30^{\prime}$ & $135^{\circ} 45^{\prime}$ & $415-449$ & 6.0 & Kasutani $^{10)}$ \\
\hline Off Wakasa Bay & $36^{\circ} 27^{\prime}$ & $135^{\circ} 43^{\prime}$ & $467-500$ & 2.0 & Ryoke $^{18)}$ \\
\hline
\end{tabular}


sledge. Therefore the number of individual crabs per $1,000 \mathrm{~m}^{2}$ that was estimated in this study reflected the population density.

Population densities per $1,000 \mathrm{~m}^{2}$ for each observation were estimated to be 1 and 4.0 at $\mathrm{M}-1,3$ at $\mathrm{M}-2,3$ at $\mathrm{M}-3,6.4$ at M-4, 10 at M-5, 5.6 at M-6, and 13 individuals at M-7, respectively (Table 1 ). Since the observation of the individuals ranged from 4 to 7 individuals at M-1, M-3, M-5 and M-7, a significant figure of the population density also corresponded to one digit. Since the significant figure of the estimation value was one digit in the surveyed areas, it was deemed necessary to improve the estimation accuracy by increasing the sweeping area (i.e. increasing the observation frequency to increase the number of observed individuals) in areas with a low population density.

Another factor that affected the estimation accuracy of the population density was the estimation accuracy of the sweeping area of the DVMSTS. Towing distance of the DVMSTS was calculated based on the position of the research vessel. The underwater video camera and the switch of the underwater light were operated by timers when the research vessel reached a steady speed and course. Since the towed sledge was stabilized and towed along a nearly straight line, based on the recorded video images, it is assumed that there was no significant error even when the towing distance was calculated based on the position of the research vessel. However, to determine more accurately the population density, it is necessary to improve the estimation accuracy of the towing distance (i.e. to increase the estimation accuracy of the sweeping area) of the DVMSTS. It is possible that the estimation accuracy of the towing distance of the DVMSTS could be raised by the use of the acoustic navigation system combined with DGPS (Differential GPS) ${ }^{20}$.

Females of the snow crab are highly aggregated compared with the males in the Sea of Japan ${ }^{1}$. Miller demonstrated that in the snow crab, both mature females and individuals smaller than $40 \mathrm{~mm}$ in carapace width were highly aggregated, whereas large males $(\geqq 70 \mathrm{~mm}$ ) displayed a random distribution around Newfoundland in Canada ${ }^{13)}$. Since the estimation of the stock abundance of the snow crab is associated with a large bias, based on the population density obtained by random sampling, it is necessary to estimate the stock abundance from the population density obtained by stratified random sampling.

For stock abundance surveys of the snow crab in Japan, trawl nets and a special type of pot have been used and the stock abundance was estimated from the amount of crab catches obtained by the survey fishing gear. In particular, since the snow crab catch is controlled by the TAC system, the stock abundance must be accurately estimated. However, presently the stock abundance of the snow crab is not estimated accurately because the sampling efficiency of the survey fishing gear has not been sufficiently evaluated ${ }^{6,16}$. To complement the use of conventional survey fishing gear, manned deep submersibles or deep-towed TV systems could be utilized ${ }^{6,19)}$. These manned deep submersibles or underwater TV systems with an umbilical cable (towed and self-propelled) have been utilized to estimate the population density of the snow $\mathrm{crab}^{6,9,10,15,17,18)}$. The use of manned deep submersibles is the most effective method to obtain detailed observations of the target species. The use of submersibles, however, is the most expensive method, and the execution of the survey is easily affected by the weather conditions $^{5,19}$. Since underwater TV systems with an umbilical cable can be conveniently handled by manpower without requiring a large support vessel, it is comparatively easy to observe the deep sea area. However, when the systems are used in the deep sea, the selection of research vessels is limited because of the need for specific winches. For ROVs, the motion in water is easily affected by an umbilical cable and the flow of the sea water. Since ROVs and manned deep submersibles are manipulated by operators, artificial bias arises when the investigators move the vehicles and submersibles to the area where target species are abundant ${ }^{4)}$. In contrast, since the DVMSTS is towed by a towline and does not need any special equipment, the DVMSTS can be used on all the research vessels. It appears that the DVMSTS could become a practical method for the survey of stock abundance, because for such a purpose, it is necessary to investigate simultaneously many stations using as many research vessels as possible. Since the observation zone of the DVMSTS corresponds to the distance between sledges, the observation zone can be fixed ${ }^{4}$. In addition, the DVMTS enables to obtain random video image samples of the target species without the artificial bias mentioned above, because the recorded videotape is retrieved on board after the observation ${ }^{4)}$. Therefore, the DVMSTS could be used to estimate the snow crab population density. However, to utilize this equipment as a quantitative survey method for the snow crab, it is necessary to improve the estimation accuracy of the population density.

\section{References}

1) Adachi, J. (1991): Distribution of snow crab Chionoecetes opilio in sea area off Hinomisaki, Shimane Prefecture where protection shelters have been installed. In JAMSTECTR Deepsea Research. ed. JAMSTEC, Kanagawa, Japan, 259-266. 
2) Adams, P. B. et al.(1995): Population estimates of Pacific coast groundfishes from video transects and swept-area trawls. Fish. Bull., 93, 446-455.

3) Fujikura, K., Tsuchida, S. \& Hashimoto, J. (2000): Density estimate of the beni-zuwai crab Chionoecetes japonicus, by an in situ observation method. Fish. Sci., 66,1183-1185.

4) Fujita, T. et al. (1994): Abundance estimation of demersal fishes in the artificial reef area by TV camera census and fishing gear sampling. Fish. Eng., 31,7-13.

5) Gilbert, T. R. \& Myriam, S. (1983): Deep-sea biology, Vol. 8. John Wiley \& Sons, Inc., New York, 81-95.

6) Hashimoto, J. \& Hotta, H. (1985): An attempt of density estimation of megalo-epibenthos by the deep towed TV system and the deep sea research submersible "SHINKAI 2000". In JAMSTECTR Deepsea Research. ed. JAMSTEC, Kanagawa, Japan, 23-35.

7) Inoue, Y., Matushita, Y. \& Goto, M. (1991): Development of underwater T.V. device worked by timer. Tech. Rep. NRIFE, Fishing gear and methods, 5, 9-14.

8) Inoue, Y., Matushita, Y. \& Goto, M. (1998): Development of timer controlled underwater video camera pack. Tech. Rep. NRIFE, 20, 23-31.

9) Kanamaru, S. \& Adachi, J. (1992): Submersible observations on the snow crab Chionoecetes opilio around artificial protection shelters, Hinomisaki, Shimane Prefecture-(I). In Proc. JAMSTEC Symp. Deep Sea Res. ed. JAMSTEC, Kanagawa, Japan, 305-312.

10) Kasutani, Y. (1993): Relations between the shape of tilled seabed and the population density of pink shrimp Pandalus borealis and snow crab Chionoecetes opilio off Wakasa Bay. In Proc. JAMSTEC Symp. Deep Sea Res. ed. JAMSTEC, Kanagawa, Japan, 361-366.

11) Kobayashi, K. \& Nagai, K. (1991): Ecological observations of the snow crab (Chionoecetes opilio), conservation reef and macrobenthic animals communities in the sea off TOTTORI Prefecture. In JAMSTECTR Deepsea Research. ed. JAMSTEC, Kanagawa, Japan, 267-275.
12) Kuwahara, A. et al.(1995): Managements of the snow crab, resource in the Western Japan Sea. Japan Fisheries Resource Conservation Association, Tokyo, 2-51 [In Japanese].

13) Miller, R. J. (1975): Density of commercial spider crab, Chionoecetes opilio, and calibration of effective area fished per trap using bottom photography. J. Fish. Res. Board Can., 32, 761-768.

14) Miyamoto, Y. et al. (2000): A fundamental study on positioning accuracy of wide area DGPS. Fish. Eng., 36, 229-235.

15) Ohashi, Y. (1993): Observation of the benthic organisms around artificial reefs which protect snow crabs from being caught in the sea off Kaga, Ishikawa Prefecture. In Proc. JAMSTEC Symp. Deep Sea Res. ed. JAMSTEC, Kanagawa, Japan, 351-359.

16) Okutani, T. (1969): Synopsis of bathyal and abyssal megalo-invertebrates from Sagami Bay and the south off Boso Peninsula trawled by the R/V Soyo-Maru. Bull. Tokai Reg. Fish. Res. Lab., 57,1-61.

17) Ryoke, K. (1991): Observations on the behavior and ecology of Tanner crab, Chionoecetes opilio, around the Tanner crab sanctuary in the Wakasa Bay using the deep-sea research submersible "SHINKAI 2000". In JAMSTECTR Deepsea Research. ed. JAMSTEC, Kanagawa, Japan, 277-282.

18) Ryoke, K. (1995): Observations of benthic organisms at a tilled seabed site off Wakasa Bay, the Sea of Japan. In Proc. JAMSTEC J. Deep Sea Res. 11. ed. JAMSTEC, Kanagawa, Japan, 415-420 .

19) Uzmann, J. R. et al.(1977):Synoptic comparison of three sampling techniques for estimating abundance and distribution of selected megafauna; submersible versus camera sled versus otter trawl. Mar. Fish. Rev., 39,11-19.

20) Watanabe, T. \& Yamasaki, S.(1999): Observation on distribution of the red queen crab Chionoecetes japonicus using the video monitoring system with a deep-sea towed sledge. Bull. J. Soc. Sci. Fish., 65, 503-504. 